\title{
Methylprednisolone pulse therapy in the treatment of polyarteritis nodosa
}

\author{
G. H. NEILD \\ M.B., M.R.C.P. \\ H. A. LEE* \\ Wessex Regional Renal Unit, St Mary's Hospital, Portsmouth, and \\ *Department of Nephrology, University of Southampton and Wessex Regional Renal Unit, \\ Portsmouth
}

\begin{abstract}
Summary
Two cases of lung granulomata associated with 'crescentic' glomerulonephritis both in a clinical setting of polyarteritis nodosa were treated with high doses of intravenous methylprednisolone ('pulse therapy') in single injections of $30 \mathrm{mg} / \mathbf{k g}$ body-weight. In the first case rapidly progressive glomerulonephritis with $100 \%$ crescents was arrested and followed by improvement of renal function from a creatinine clearance of $5 \mathrm{ml} / \mathrm{min}$ to $30 \mathrm{ml} / \mathrm{min}$; in the second case multiple lung granulomata of 8 months' standing, unresponsive to oral steroids, disappeared 8 days after treatment with high dosage intravenous methylprednisolone.

The use of 'pulse therapy' with methylprednisolone is advocated, not only in such cases where arteritis is known or suspected, but also in rapidly progressive glomerulonephritis associated with crescents.
\end{abstract}

\section{Introduction}

The treatment of polyarteritis nodosa (PAN) with high dose oral corticosteroids is not always successful and frequently complicated by the high attendant morbidity of the steroids. Moreover rapidly progressive glomerulonephritis (a clinico-pathological entity characterized by a rapid deterioration in renal function in days or weeks and histologically by extensive epithelial cell proliferation forming crescents that occlude Bowman's space) has, whatever the cause, almost always a fatal outcome. When this is associated with polyarteritis nodosa the outcome untreated is always fatal (Harrison, Loughridge and Milne, 1964).

Impressed by the lack of toxicity of high doses of intravenous methylprednisolone $(30 \mathrm{mg} / \mathrm{kg}$ body-

Correspondence: Professor H. A. Lee, Department of Nephrology, University of Southampton and Wessex Regional Renal Unit, Portsmouth PO3 6AD. weight) in renal transplantation work and the reduction in steroid-associated morbidity that they have seen in the past 4 years at the Wessex Regional Renal Unit, the authors treated a patient with rapidly progressive glomerulonephritis associated with a lung granuloma in whom the clinical diagnosis was polyarteritis nodosa. This recovery was so impressive that they were encouraged to use similar treatment in a patient with clinical polyarteritis nodosa and multiple recurrent lung granulomata in whom severe steroid morbidity, particularly multiple? vertebral collapse discouraged any further increase in his oral dosage of steroids. Again the rapidity of sustained improvement was very impressive.

The two cases are described and the implications discussed.

\section{Case 1}

A 59-year-old man working on a refrigerator assembly line had been perfectly well until 5 weeks before hospital admission, when he had an influenzalike illness, which never completely cleared. Sixteen days before admission he had an acute arthritis of the right ankle. This soon settled with analgesics but was followed by malaise, pyrexia and myalgia in the neck and shoulders. He was given amoxycillin. He developed painful mouth ulcers and 5 days before admission a left foot drop.

On examination, he had a petechial rash over his arms and lower legs and small vasculitic lesions around his nail beds and finger tips, associated with pinhead size areas of skin necrosis. A chest X-ray showed a mass in his right upper lobe. His haemoglobin was $10.7 \mathrm{~g} / \mathrm{dl}$, WBC $27 \times 10^{9} / 1(27 \%$ eosinophilia), ESR $80 \mathrm{~mm} / \mathrm{hr}$ and blood urea 10.5 $\mathrm{mmol} / \mathrm{l}$. He had gross microscopic haematuria. Bronchoscopy excluded carcinoma of the lung and cultures were negative for acid fast bacilli. A random 
leg muscle biopsy was normal and a skin biopsy of a necrotic area was unsuccessful. During the first 2 weeks of admission his blood urea rose gradually to $40 \mathrm{mmol} / \mathrm{l}$; his urine output and blood pressure remained normal.

When transferred his rash had disappeared, he had severe mouth ulcerations and his skin necroses were unchanged. Blood pressure was $14 \cdot 6 / 10 \cdot 0 \mathrm{kPa}$ standing and lying; he had a soft early ejection systolic murmur at the apex, his chest was clinically clear. There was weakness of the left foot dorsiflexion and impaired sensation over the lateral side of his left lower leg and foot. His fundi were normal. In his abdomen his liver was just palpable. Haemoglobin was $7.4 \mathrm{~g} / \mathrm{dl}$, WBC $17 \times 10^{9} / 1$ (eosinophils 1.9 neutrophils $14 \cdot 2$ ), ESR $80 \mathrm{~mm} / \mathrm{hr}$ and reticulocytes $1 \%$. Heparin neutralizing activity 60 (N25-35), thrombin clotting time 32 (21-26), British Prothrombin Ratio 1.2, CKT 44 (control 45). Blood urea $40 \mathrm{mmol} / \mathrm{l}$, creatinine $0.66 \mathrm{mmol} / \mathrm{l}$, endogenous creatinine clearance $5 \mathrm{ml} / \mathrm{min}$. Alkaline phosphatase $214 \mathrm{u} . / 1$, serum albumin $21 \mathrm{~g} / \mathrm{l}$. Australia antigen and antibody negative. Antinuclear factor negative, sheep-cell agglutination test 1 in 40 , otherwise autoimmune profile negative. Serum immunoglobulins and complement normal. Antistreptolysin titre less than $1: 50$. Urine microscopy showed 3-6 RBC/high power field and occasional granular casts. Proteinuria ranged from 0.4-1.3 g/day. Urinary fibrinogen degradation products less than $2 \mu \mathrm{g} / \mathrm{ml}$. Viral antibodies showed recent influenza A infection.

A percutaneous renal biopsy was done on the day of referral. Seventeen glomeruli were seen. All showed florid crescent formation with total or partial compression of the glomerular tuft in which there was minimal evidence of cellular proliferation. No necroses were seen. In addition there was extensive tubular damage, with marked diffuse eosinophil and plasma cell infiltration in the already fibrotic interstitium. There was no evidence of arteritis (Fig. 1).
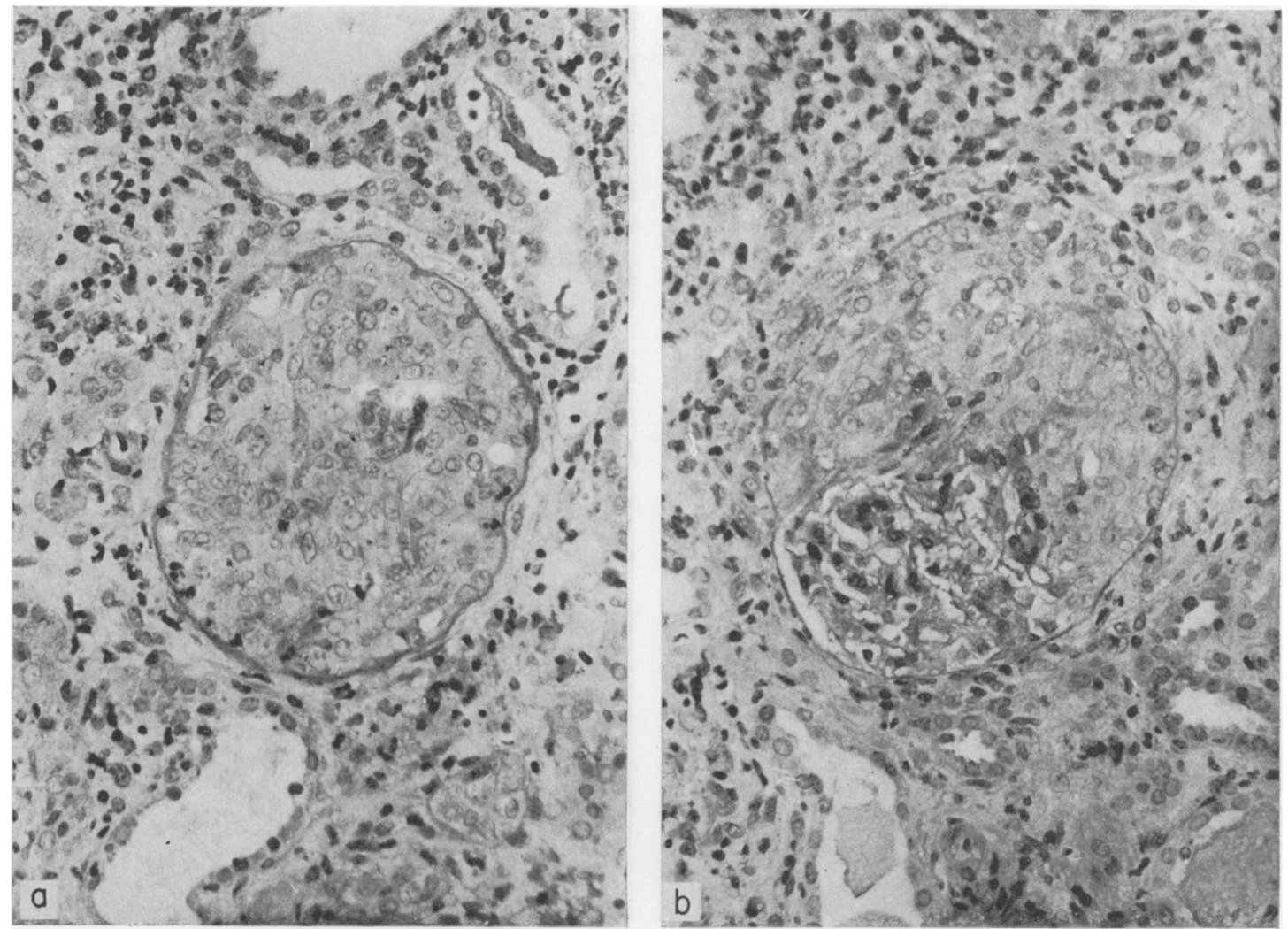

FIG. 1. (a) Case 1: glomerular epithelial cell proliferation totally obliterating the glomerulus. No glomerular tuft is discernible. (b) Two-thirds of Bowman's space occluded by epithelial cell proliferation. The compressed glomerular tuft shows at most minimal mesangioproliferation. Both figures show interstitial oedema with a marked round cell interstitial infiltrate. There is dilatation of some proximal tubules with flattening of the columnar cells. All P.A.S. stain $\times 350$. 
A diagnosis of very severe rapidly progressive glomerulonephritis with $100 \%$ crescents, a solitary lung granuloma, in a clinical setting of polyarteritis nodosa was made although histologically no arteritis was demonstrated.

He was treated with intravenous 'pulses' of methylprednisolone $1500 \mathrm{mg}(30 \mathrm{mg} / \mathrm{kg}$ body-weight), four times at 48 -hr intervals. He was also put on a 'background' dose of prednisolone $20 \mathrm{mg} /$ day.

There was no further decline in his renal function. His serum creatinine fell very slowly to $0.5 \mathrm{mmol} / \mathrm{l}$ and his urine output remained at 1-2 1/day. A salt depletion episode complicated his recovery.

With salt repletion his creatinine fell rapidly to $0.2 \mathrm{mmol} / 1$ and the creatinine clearance rose to 20 $\mathrm{ml} / \mathrm{min}$. After 4 weeks he was re-biopsied. Repeat biopsy showed twenty-one of the twenty-five glomeruli to be obsolescent, three glomeruli appeared almost uninvolved showing only minimal mesangioproliferation (Fig. 2). There was very severe tubular atrophy and diffuse interstitial fibrosis.

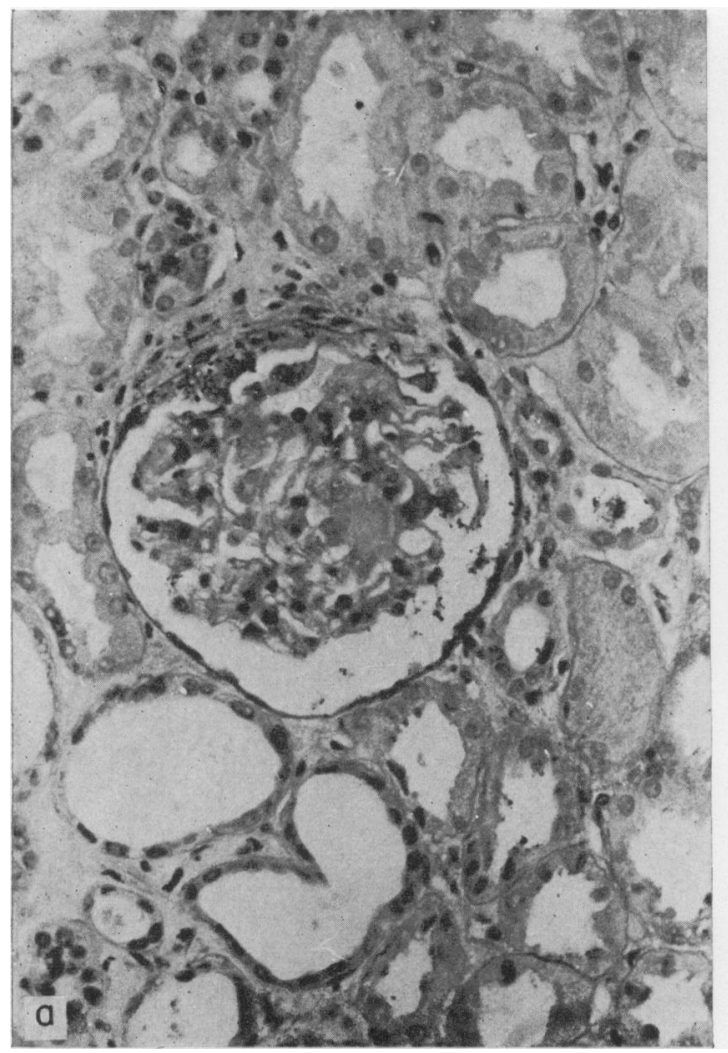

His lung granuloma had disappeared within 14 days of starting his steroid therapy. His footdrop improved gradually during his stay. His mouth ulcers cleared in 2 weeks. Three months after admission his steroids had been reduced to $7.5 \mathrm{mg} /$ day, his creatinine clearance had risen to $30 \mathrm{ml} / \mathrm{min}$ and he was back at work.

\section{Case 2}

This 27-year-old male presented in March 1969 with haemoptysis following a cold. A chest X-ray showed a medium sized cavity at the left apex and a small one at the right apex.

Investigations: repeated sputa for acid fast bacilli were negative; Heaf test was negative; ESR $50 \mathrm{~mm} / \mathrm{hr}$. He was started on streptomycin and sodium aminosalicylate, but the streptomycin was stopped after 10 days when he developed vertigo. Over the next year the cavities became smaller. In September 1970 the left cavity increased and developed the appearance of a mycetoma. He was admitted in November

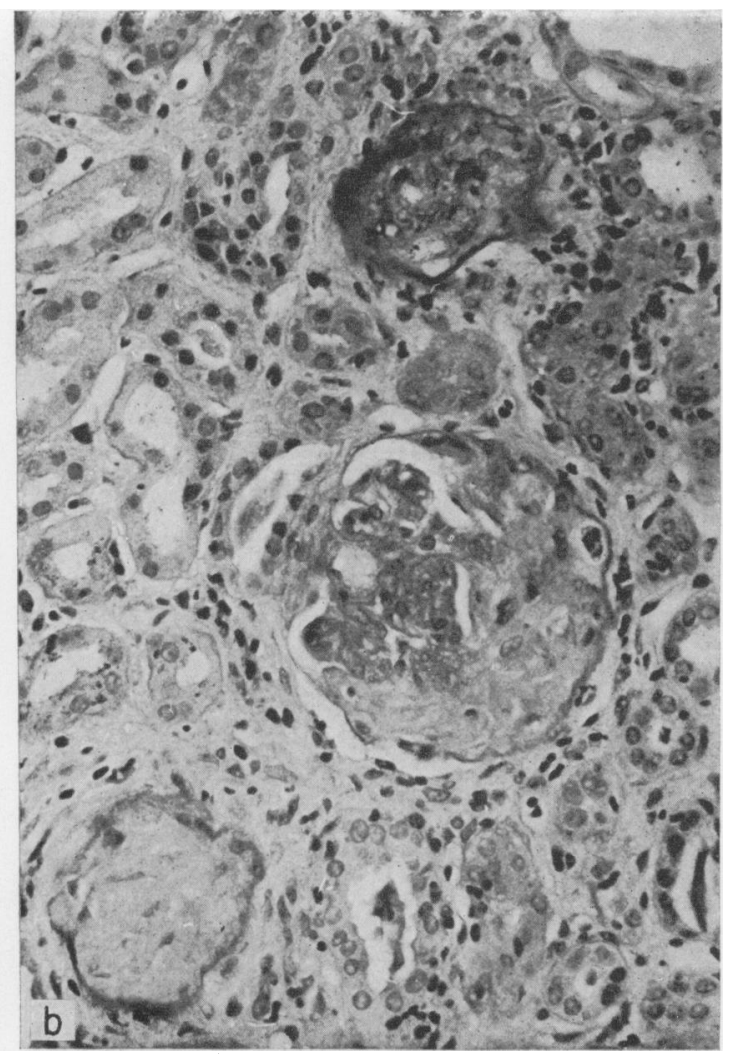

FIG. 2. (a) Case 1: shows two sclerosed, obsolescent glomeruli, and one glomerulus with a fibrosed crescent and a collapsed, probably obsolescent glomerular tuft. (b) One almost normal glomerulus showing a mild mesangioproliferation. Both figures show a marked reduction in the interstitial infiltrate with patchy early interstitial fibrosis. There is tubular regeneration. All P.A.S. stain $\times 350$. 
1970 and the apical and posterior segments of the left upper lobe were resected. Investigations: haemoglobin $14.6 \mathrm{~g} / \mathrm{dl}$, WBC $8 \times 10^{9} / 1$, ESR $37 \mathrm{~mm} / \mathrm{hr}$; Aspergillus fumigatus was grown from the cavitated mass removed. Histologically there was no evidence of tuberculosis. Six weeks later he was admitted with a multisystem disorder. This started with arthralgia of the knees and shoulders progressing to a generalized arthralgia and then swelling of the larger joints. He also complained of mouth ulceration. On examination he looked thin and ill, he had episceleritis, a few splinter haemorrhages in his nails, petechial haemorrhages over both feet, swollen painful joints, the liver and spleen were just palpable. Investigations: haemoglobin $12.7 \mathrm{~g} / \mathrm{dl}$, WBC $10.8 \times 10^{9} / 1$ with $12 \%$ eosinophils, ESR $54 \mathrm{~mm} / \mathrm{hr}$, blood urea was $5.6 \mathrm{mmol} / \mathrm{l}$, latex test was weakly positive. Urine microscopy showed occasional granular casts and red blood cells. There was ++ proteinuria. On the fifth day in hospital he had a large gastrointestinal haemorrhage, requiring an 8-pint blood transfusion. It was considered he had an arteritic lesion involving the colon and he was started on steroids. In the next 4 months he developed, at different times, rightsided epididymo-orchitis, skin ulceration over one foot, severe right hypochondrial pain with fever and diarrhoea, followed by an episode of jaundice. In April 1971 he was first seen at St Mary's Hospital. He had persistent microscopic haematuria, proteinuria up to $3 \cdot 3 \mathrm{~g} /$ day and a creatinine clearance of $57 \mathrm{ml} / \mathrm{min}$. An intravenous pyelogram showed normal size kidneys. A renal biopsy showed a mesangioproliferative glomerulonephritis with crescents. Two-thirds of the glomeruli were completely sclerosed. There was no evidence of arteritis or of necrosis in the glomerular tufts. He remained well on $20 \mathrm{mg}$ prednisolone per day for 1 year and then between April and November 1972 his steroids were gradually stopped. He remained perfectly well at work until December 1973. His renal function was steady (creatinine clearance $50 \mathrm{ml} / \mathrm{min}$ ) and he had persistent proteinuria up to $2 \mathrm{~g} /$ day.

He re-presented with right orchitis, arthralgia and raised tender areas on his legs. Chest X-ray showed recurrence of the bilateral apical lesions with cavities and he was restarted on prednisolone $45 \mathrm{mg} /$ day. Haemoglobin was $12.4 \mathrm{~g} / \mathrm{dl}$ and ESR was $88 \mathrm{~mm} / \mathrm{hr}$. Australia antigen and antibody negative. The steroids were soon reduced to a maintenance dose of 15 $\mathrm{mg} /$ day. Clotrimazole therapy was begun for an assumed $A$. fumigatus colonization again of a left apical lesion. He remained unwell with an ESR above $100 \mathrm{~mm} / \mathrm{hr}$ and he developed a mononeuritis affecting his right ulnar nerve.

In August he suddenly developed massive cavitating lesions throughout both lung fields; the steroids were increased to $45 \mathrm{mg} /$ day and azathio- prine $150 \mathrm{mg} /$ day started. In October he had a stress fracture of the fourth left metatarsal. In November he had a gastrointestinal haemorrhage requiring a 6-pint blood transfusion.

By January 1975, although the lung granulomata had cleared, he was Cushingoid and complained of a painful back; X-rays showed marked osteoporosis and multiple collapse of thoracic vertebrae. Bilateral early cataracts had developed and the steroids were gradually reduced to $15 \mathrm{mg} /$ day. He also became hypertensive and was started on propranolol. His creatinine clearance had fallen to $25 \mathrm{ml} / \mathrm{min}$. For the rest of the year he remained relatively well and continued to work. In December 1975 granulomata reappeared and by April 1976 were increased in size and number in both lungs though without pulmonary symptomatology (Fig. 3). In view of the previous steroid-induced complications it was decided to treat him with intravenous 'pulses' of methylprednisolone every other day for four doses. Within 8 days of starting, the granulomata had disappeared (Fig. 4). However, owing to his severe immobility he did not otherwise improve and, despite enthusiastic attempts at mobilization, his severe back pain became incapacitating and he died in June.

\section{Discussion}

Before the introduction of steroids, polyarteriti nodosa (PAN) was ultimately fatal in most casesp although death was sometimes not due to active arteritis but to the sequelae of lesions where active disease had ceased (M.R.C. Report, 1957). Steroids have been shown to modify the course and improve the symptoms of PAN although not improving overall survival time: although one year survival figures are much improved by steroids, at 3 years there is no advantage (M.R.C. Report, 1960; Frohnert and Sheps, 1967). However, in PAN and other collagen diseases, to suppress disease activity very large maintenance doses of steroids may need to be given and the attendant morbidity may become more serious or disabling than the disease itself. Among the complications are osteoporosis leading to vertebral collapse with pain and neurological complications, diabetes mellitus, myopathy, cosmetic problems, cataracts and haemorrhage from peptic ulceration.

Very high doses of intravenous steroids ('pulses', $30 \mathrm{mg} / \mathrm{kg}$ body-weight) have been used for several years to reverse organ transplant rejection and their efficacy has been proved (Bell et al., 1971; Feduska et al., 1972).

Recently Cathcart et al. (1976), have described the use of intravenous 'pulses' of high doses of methylprednisolone in diffuse proliferative lupus nephritis with rapid deterioration of renal function. They were initially impressed by the histological appearances in a renal biopsy of one such patient and its similarities 


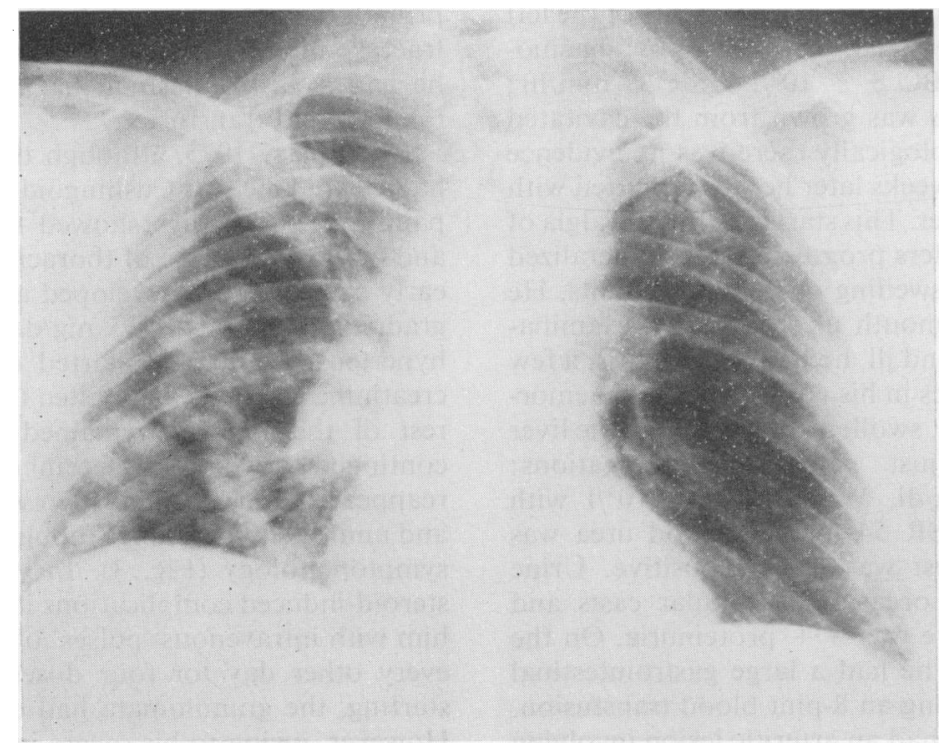

Fig. 3. Case 2: widespread lung granulomata present before start of methylprednisolone therapy.

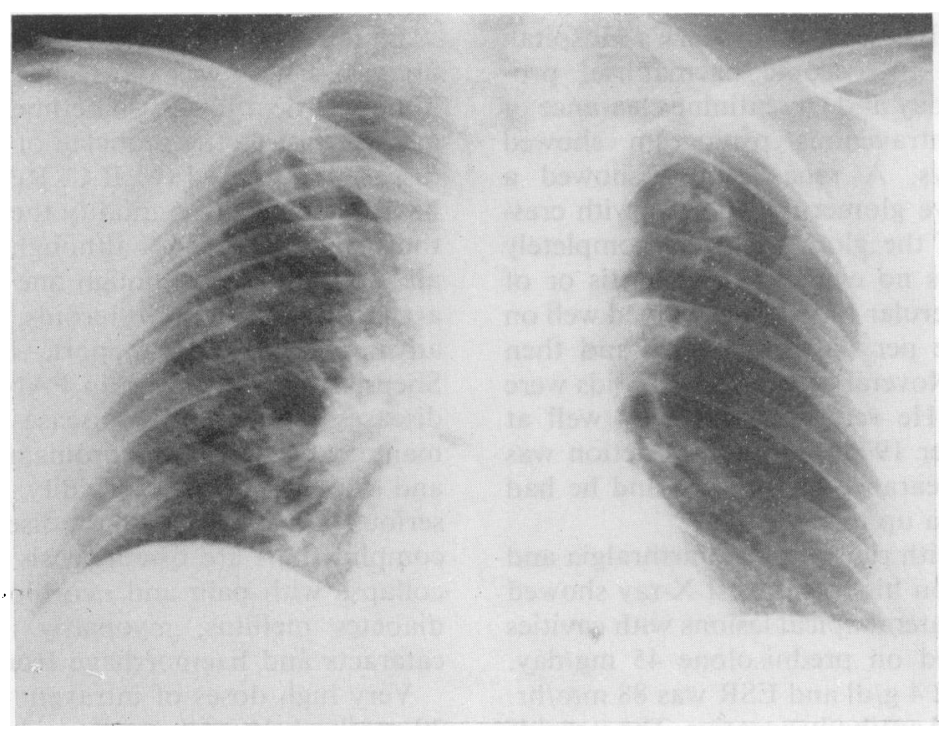

with acute renal transplant rejection. In all five cases there was a rapid improvement in renal function with a return to baseline creatinine levels in 1 month.

This group of patients would be treated in some other units with a mixture of steroids, azathioprine, dipyridamole and anti-coagulants as popularized by Kincaid-Smith's unit in Melbourne (Kincaid-Smith, Saker and Fairley, 1968; Brown et al., 1974).

The use of steroids in PAN and in other collagen diseases is empirical. The mechanism of action is 
unknown as are the aetiologies and pathogeneses of the diseases they are used in. By analogy with vascular lesions seen in animal experimental models of acute serum sickness (Dixon et al., 1958), PAN is thought to be a soluble immune complex disease in which complexes are deposited in vessel walls initiating inflammatory responses, which are neutrophil mediated and resulting in arteritic lesions. Arteritic lesions are found in other 'soluble complex diseases' such as systemic lupus erythematosus and rheumatoid arthritis (Sokoloft, 1963), cryoglobulinaemia (Case Records, 1974), post-streptococcal nephritis (Fordham et al., 1964) and Wegener's granulomatosis (Howell and Epstein, 1976). In PAN Australia antigen-antibody ( $\mathrm{Ag}-\mathrm{Ab})$ complexes have occasionally been found in the blood and incriminated in the pathogenesis of the arteritis (Gocke et al., 1970), but never has the complex actually been identified in the arteritic lesion.

In these diseases steroids act to suppress tissue inflammation and possibly to inhibit the formation of soluble $\mathrm{Ag}-\mathrm{Ab}$ complexes, either by dissociation of the complexes or by alteration of the quality or quantity of the antibodies or antigens. Although the mechanisms of action of steroids are unknown, high doses of intravenous methylprednisolone have been shown to inhibit neutrophil accumulation in injured tissue (Weiner et al., 1975).

High oral doses of prednisolone have been shown to be lympholytic resulting in $\mathrm{T}$ and to a lesser degree B cell lymphopenia (Yu et al., 1974). Short courses of high oral doses of methylprednisolone produce a fall in serum IgG levels by an increase in catabolism during the drug administration and a decrease in IgG synthesis, both during administration and for a variable time afterwards (Butler and Rossen, 1973).

Both these cases had lung granulomata associated with crescentic glomerulonephritis as part of a multi-system disorder typical of polyarteritis nodosa, although no arteritic lesions were seen in either of the renal biopsies.

In case 2 lung granulomata disappeared most dramatically in 8 days after intravenous methylprednisolone whereas previously they had taken 6-8 months to disappear on high doses of oral prednisolone. In case 1 rapidly progressive renal failure was arrested and then gradually improved from a creatinine clearance of $5.0 \mathrm{ml} / \mathrm{min}$ to $30 \mathrm{ml} / \mathrm{min}$, although, residual renal damage, as judged by a second biopsy was severe. The solitary apical lung granuloma disappeared in 2 weeks and after 1 month he was well and at home.

Although the use of steroids remains empirical in any dose, its efficacy has been shown. It is suggested that high dose intravenous methylprednisolone may rapidly and effectively suppress active symptoms and lesions and the patient may then be maintained, if necessary, on smaller less harmful doses of steroids.

\section{References}

Bell, P.R.F., Calman, K.C., Wood, R.F.M., Briggs, J.D., Paton, A.M. \& MacPherson, S.G. (1971) Reversal of acute clinical and experimental organ rejection using very large doses of intravenous prednisolone. Lancet, $\mathbf{i}$, 876.

Brown, C.B., Turner, O., OgG, C.S., Wilson, D., Cameron, J.S., Chantler, C. \& Gill, D. (1974) Combined immunosuppression and anticoagulation in rapidly progressive glomerulonephritis. Lancet, ii, 1166.

Butler, W.T. \& Rossen, R.D. (1973) Effects of corticosteroids on immunity in man. Journal of Clinical Investigation, 52, 2629.

Case Records of the Massachussetts General Hospital (1974) New England Journal of Medicine, 291, 1073.

Cathcart, E.S., Idelson, B.A., Scheinberg, A. \& Couser, W.G. (1976) Beneficial effects of methylprednisolone 'pulse' therapy in diffuse proliferative lupus nephritis. Lancet, i, 163.

Dixon, F.J., Vazques, J.J., Weigle, W.O. \& Cochrane, C.G. (1958) Pathogenesis of serum sickness. Archives of Patho$\log y, 65,18$.

Feduska, N.J., Turcotte, J.G., Gikas, P.W., Bacon, G.E. \& PENNER, J.A. (1972) Reversal of renal allograft rejection with intravenous methylprednisolone 'pulse' therapy. Journal of Surgical Research, 12, 208.

Fordham, C.G., III, Epstein, F.A., Huffines, W.D. \& HARRINGTON, J.T. (1964) Polyarteritis and acute post
streptococcal glomerulonephritis. Annals of Interna Medicine, 61, 89.

Frohnert, P.P. \& ShePs, S.G. (1967) Long term follow-up study of periarteritis nodosa. American Journal of Medicine, $43,8$.

Gocke, D.J., Morgan, C., Locksin, M., Hsu, K., BomarDier, S. \& Christian, C. (1970) Association between polyarteritis and Australia antigen. Lancet, ii, 1149.

Harrison, C.V., Loughridge, L.W. \& Milne, M.D. (1964) Acute oliguric renal failure in acute glomerulonephritis and polyarteritis nodosa. Quarterly Journal of Medicine, 33, 39.

Howell, S.B. \& EPSTEIN, W.V. (1976) Circulating immunoglobulin complexes in Wegener's granulomatosis. American Journal of Medicine, 60, 259.

Kincaid-Smith, P., SAKer, B.M. \& Fairley, K.F. (1968) Anti-coagulants in 'irreversible' acute renal failure. Lancet ii, 1360.

M.R.C. Report on treatment of polyarteritis nodosa with cortisone: results after one year. (1957) British Medical Journal, 1, 608.

M.R.C. Report on treatment of polyarteritis nodosa with cortisone: results after three years. (1970) British Medical Journal, 1, 1399.

Sokoloft, L. (1963) The Pathophysiology of Peripheral Blood Vessels in Collagen Diseases. The Peripheral Blood Vessels (Ed. by J. H. Orbinson and C. E. Smith), pp. 297-325. Williams and Wilkins, Baltimore.

Weiner, S.C., Weiner, R., Urivetsky, M., Shaefer, S., Isenberg, H.D., JaNov, C. \& MeIlman, E. (1975) The mechanism of action of a single dose of methylprednisolone on acute inflammation in vivo. Journal of Clinical Investigation, 56, 679 .

Yu, D.T.Y., Clements, P.J., Paulus, H.E., Peter, J.B., LEVY, J. \& BARNET, E.V. (1974) Effects of corticosteroids on human lymphocyte sub-populations. Journal of Clinical Investigation, 53, 565. 